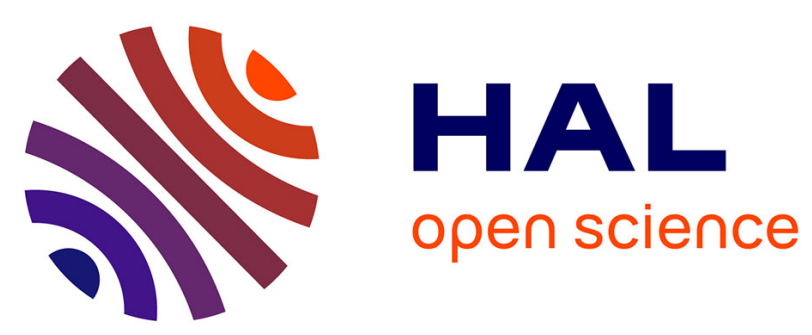

\title{
APPLICATION OF A NEW PROGRAM OF CONVERSION-SPECTRUM ANALYSIS, ACSEMP, TO THE DERIVATION OF OUTER-SHELL s-ELECTRON DENSITY OF Fe
}

M. Fujioka, M. Takashima

\section{To cite this version:}

M. Fujioka, M. Takashima. APPLICATION OF A NEW PROGRAM OF CONVERSIONSPECTRUM ANALYSIS, ACSEMP, TO THE DERIVATION OF OUTER-SHELL s-ELECTRON DENSITY OF Fe. Journal de Physique Colloques, 1979, 40 (C2), pp.C2-32-C2-35. 10.1051/jphyscol:1979210 . jpa-00218468

HAL Id: jpa-00218468 https://hal.science/jpa-00218468

Submitted on 1 Jan 1979

HAL is a multi-disciplinary open access archive for the deposit and dissemination of scientific research documents, whether they are published or not. The documents may come from teaching and research institutions in France or abroad, or from public or private research centers.
L'archive ouverte pluridisciplinaire HAL, est destinée au dépôt et à la diffusion de documents scientifiques de niveau recherche, publiés ou non, émanant des établissements d'enseignement et de recherche français ou étrangers, des laboratoires publics ou privés. 


\title{
APPLICATION OF A NEW PROGRAM OF CONVERSION-SPECTRUM ANALYSIS, ACSEMP, TO THE DERIVATION OF OUTER-SHELL $S$-ELECTRON DENSITY OF $\mathrm{Fe}$
}

\author{
M. Fujioka and M. Takashima \\ Cyclotron-Radioisotope Center and Department of Physies, Tohoku University, Sendai, Japan
}

\begin{abstract}
Résumé.-Un nouveau programme a été appliqué à la conversion interne des hautes couches de la transition $14,4 \mathrm{keV}$ de ${ }^{57} \mathrm{Fe}$. A I'aide de ce programme on peut optimiser les profils de ligne de conversion à partir des profils initiaux déterminés empiriquement. Par conséquent on obtient la densitê de contact $4 \mathrm{~s}$ de ${ }^{57} \mathrm{Fe}$ et $1^{\prime}$ erreur sur cette densité par une prise en compte automatique des incertitudes sur profils de conversion. I1 a été démontré que 1 'erreur rattachée à $1 \mathrm{a}$ densitê $4 \mathrm{~s}$ est bien rêduite en comparaison de la méthode précédente.

Abstract.- A new program of conversion-spectrum analysis has been applied to the outer-shell conversion of the $14.4 \mathrm{keV}$ transition of ${ }^{57} \mathrm{Fe}$. The program allows for optimization of the line profiles starting from the initial ones estimated empirically. Thus the program gives the 4 s-electron density of ${ }^{57} \mathrm{Fe}$ together with its error which automatically considers uncertainties of the profiles. It is shown that the error attached to the $4 \mathrm{~s}$ density can be considerably reduced as compared with the previous method.
\end{abstract}

1. Introduction.- Internal conversion is a unique method whereby one can obtain the contact charge density of s-electrons of individual shelis of the atom, especially, the s-electron density of the valence she11 $/ 1 /$. In order to extract the s-electron density from a measured spectrum, one must resort to e.g., a least-squares analysis, assuming some profiles for the component conversion lines. Usually, one takes some analytical function of electron momentum having parameters which describe these profiles $/ 2 /$. In this case it is easy to incorporate optimization of profiles into the algorithm of a least-squares analysis. However, for conversion spectra of rather low energy, as is the case of ${ }^{57} \mathrm{Fe}$, the converted electrons are subject to inelastic scattering, showing irregular line profiles due to discrete energy losses $/ 3,4 /$. In this case it is difficult to choose such an analytical function that is applicable irrespectively of the source sample. Thus in our previous analysis of conversion spectra of ${ }^{57} \mathrm{Fe}$ we employed empirical profiles $/ 1,5,6 /$. The difficulty here lies in estimating the errors which should arise from probable errors of the profiles themselves, and hence we used an intuitive method in estimating this part of the errors $/ 1 /$.

In this paper we give a brief account of a new program, ACSEMP (Analysis of Conversion Spectra using EMpirical Profiles) which optimizes the profiles as well as the line positions starting from the initial ones, and apply it to ${ }^{57} \mathrm{Fe}$ in Fe metal. We compare the result obtained by this scheme with that of the previous method, ACSLSF (Analysis of Conversion Spectra using simple Least-Squares
Fitting) combined with the intuitive error estimation of the profiles.

2. Outline of the program.- In the case of ${ }^{57} \mathrm{Fe}$, the program accepts initial profiles (in numerical form) for $M_{1}(3 s)$ and $N_{1}(4 s)$ conversion lines; for the necessity of different profiles for $\mathrm{M}_{1}$ and $\mathrm{N}_{1}$ lines, see references $/ 7,8 /$. The profiles of $M_{2}, 3(3 p)$ is identified as that of $M_{1}$. The process of adjustment of profiles closely parallels a manual one. Take two pairs of continuation points $\left(l_{1}, l_{2}\right)$ and $\left(h_{1}, h_{2}\right)$ for low- and high-energy tails, respectively. Here we define the low- and high-energy tails by $x \leqslant 1_{1}$ and $x \geqslant h_{2}$, respectively, and the peak region by $1_{2} \leqslant x \leqslant h_{1}$. Adjustment of profiles is represented by five incremental quantities; $\mathrm{dH}_{1}$ (low-energy tail height), $\mathrm{dG}_{1}$ (low-energy tail gradient), $\mathrm{dH}_{\mathrm{h}}$ (highenergy tail height), $d W_{1}\left(M_{1}\right.$ peak width) and $d W_{2}$ $\left(\mathrm{N}_{1}\right.$ peak width). Each time these incremental changes are executed, the resulting discontinuities are removed by smooth continuation curves through the continuation regions $\left[1_{1}, 1_{2}\right]$ and $\left[h_{1}, h_{2}\right]$. The least-squares analysis is performed in three steps; 1) only the Iine and background intensities are adjusted, 2) adjustment of line positions is added and 3) full adjustment of all the parameters is performed. In this report we add another step, 4) readjustment of only the line and background intensities, in order to separate the corresponding errors. In the third step the adjustment is repeated several times. During the adjustment of profiles the program follows the rule of constant tail-fraction; tail fraction should be the same for $M_{1}$ and $N_{1}$ 
profiles $/ 8 /$.

The error estimate of intensity ratios of conversion lines is due to the standard procedure using the relevant error matrix. The normalized chi-squares, $X^{2}{ }_{N}\left(x^{2}\right.$ divided by the number of degrees of freedom), is evaluated and the error matrix is multiplied by $\mathrm{X}_{\mathrm{N}}{ }^{2}$ if it is larger than unity. Thus the estimated errors (step 3) automatically include those arising from uncertainties of the profiles employed in decomposing the spectrum.

3. Results and Discussions.- The initial profiles were constructed using the experimental spectrum to be analysed and that of the reference source according to the deconvolution and constant-tail-fraction procedures described in reference /8/. In addition, the low-energy tail of the profiles was intentionally deformed in order to see the profile-adjusting capability of the program. The results of the analysis are shown in figure 1 and table $I$.

As is seen from figure 1, the present program can properly correct inappropriate initial profiles (low energy tail) as well as positions. It is also noted that the amount of high-energy tail is considerably reduced as a result of profile adjustment. In table I the large value of tail fraction (50 60\%) clearly demonstrates the importance of the rule of constant tail-fraction in deriving accurate intensity ratios of conversion lines.
In table I column $C$ represents the full result of ASCEMP, while column D simulates the previous program ACSLSF. One can see that $\chi_{N}{ }^{2}$ and $\sigma_{0}\left(N_{1} / M_{1}\right)$ of $C$ are slightly larger than the corresponding values of $D$, while $\sigma_{0}\left(M_{2,3} / M_{1}\right)$ of $C$ is considerably larger than that of $D$. This means that uncertainties of profiles, especially, those of high-energy tail can give a large error to the $\mathrm{M}_{2,3}$ intensity, while they add only slightly to the error of $\mathrm{N}_{1}$ intensity.

Now let us compare the error estimate of $\mathrm{C}$, $\left(\sigma_{0}\right)_{C}$, with that of $D$ combined with the intuitive error estimate of uncertainties of profiles, $(\sigma)_{D}$; see table I! It is seen that $(\sigma)_{D}$ are considerably larger than $\left(\sigma_{0}\right) \mathrm{C}$. This means that the intuitive method over-estimates the errors of relative line intensities, and hence gives an unduly large error to the $4 \mathrm{~s}$ density extracted from the conversion spectrum. Adopting the exror estimate of $\mathrm{C}$, the $4 \mathrm{~s}$ density of ${ }^{57} \mathrm{Fe}$ in $\mathrm{Fe}$ metal is obtained as shown in table $I$. The present value is consistent with our previous analysis with intuitive error estimate of profile uncertainties, $\rho_{4 \mathrm{~s}}(0)=5.53 \pm 0.46 \mathrm{a}_{0}^{-3} / 7 /$, and has a considerably reduced error.

The authors are grateful to Dr T. Shinohara and $\operatorname{Pr} \mathrm{T}$. Ishimatsu for discussions, and to $\operatorname{Pr} \mathrm{S}$. Morita for his interest in this work.

Table I : Results of least-squares analysis of the conversion spectrum of $14.4 \mathrm{keV}$ transition of ${ }^{57} \mathrm{Fe}$ in Fe metal using ACSEMP (a)

\begin{tabular}{|c|c|c|c|c|}
\hline & A & B & c & D \\
\hline Adjusted quantities & Intensities & $\begin{array}{c}\text { Intensities } \\
\text { Positions } \\
\end{array}$ & $\begin{array}{l}\text { Intensities } \\
\text { Fositions Profiles }\end{array}$ & Intensities \\
\hline Tail fraction & $57.7 \%$ & $57.7 \%$ & $51.1 \%$ & $51.1 \%$ \\
\hline$x_{N}^{2}$ & 7.88 & 3.30 & 1.46 & 1.36 \\
\hline $\mathrm{M}_{2,3} / \mathrm{M}_{1} \pm \sigma_{0} \quad\left(\sigma^{\mathrm{b}}\right)$ & $0.0725 \pm 0.0065$ & $0.0615 \pm 0.0044$ & $0.0734 \pm 0.0040$ & $\begin{array}{r}0.0734 \pm 0.0028 \\
(0.0077)\end{array}$ \\
\hline $\mathrm{N}_{1} / \mathrm{M}_{1} \pm \underset{(\sigma)}{\sigma_{0}} \quad\left({ }^{\mathrm{b}}\right)$ & $0.0421 \pm 0.0039$ & $0.0433 \pm 0.0026$ & $0.0449 \pm 0.0017$ & $\begin{array}{r}0.0449 \pm 0.0016 \\
(0.0035)\end{array}$ \\
\hline$\rho_{45}(0) \quad(c)$ & & & $5.86 \pm 0.23 \mathrm{a}_{0}^{-3}$ & \\
\hline
\end{tabular}

(a) Columns A, B, C and D correspond to a), b), c) and d) of figure 1, respectively. Intensity ratios of conversion line are denoted as $\mathrm{M}_{2,3} / \mathrm{M}_{1}$ and $\mathrm{N}_{1} / \mathrm{M}_{1}$.

(b) The errors due to uncertainties of profiles were estimated according to reference $/ 1 /$, and were combined with the computer results.

(c) The $4 \mathrm{~s}$ density was obtained as $\rho_{4 \mathrm{~S}}(0)=(136 \pm 2) \mathrm{a}_{0}^{-3}\left(\mathrm{~N}_{1} / \mathrm{M}_{1}\right) \times(1-0.03-0.01)$, where the theoretical value of $\rho_{3 \mathrm{~S}}(0)=136 \pm 2 \mathrm{a}^{-3}$ and corrections of valence p-electrons $(-3 \%)$ and of core $3 \mathrm{~d}$-electrons $(-1 \%)$ were employed $/ 6 /$. 

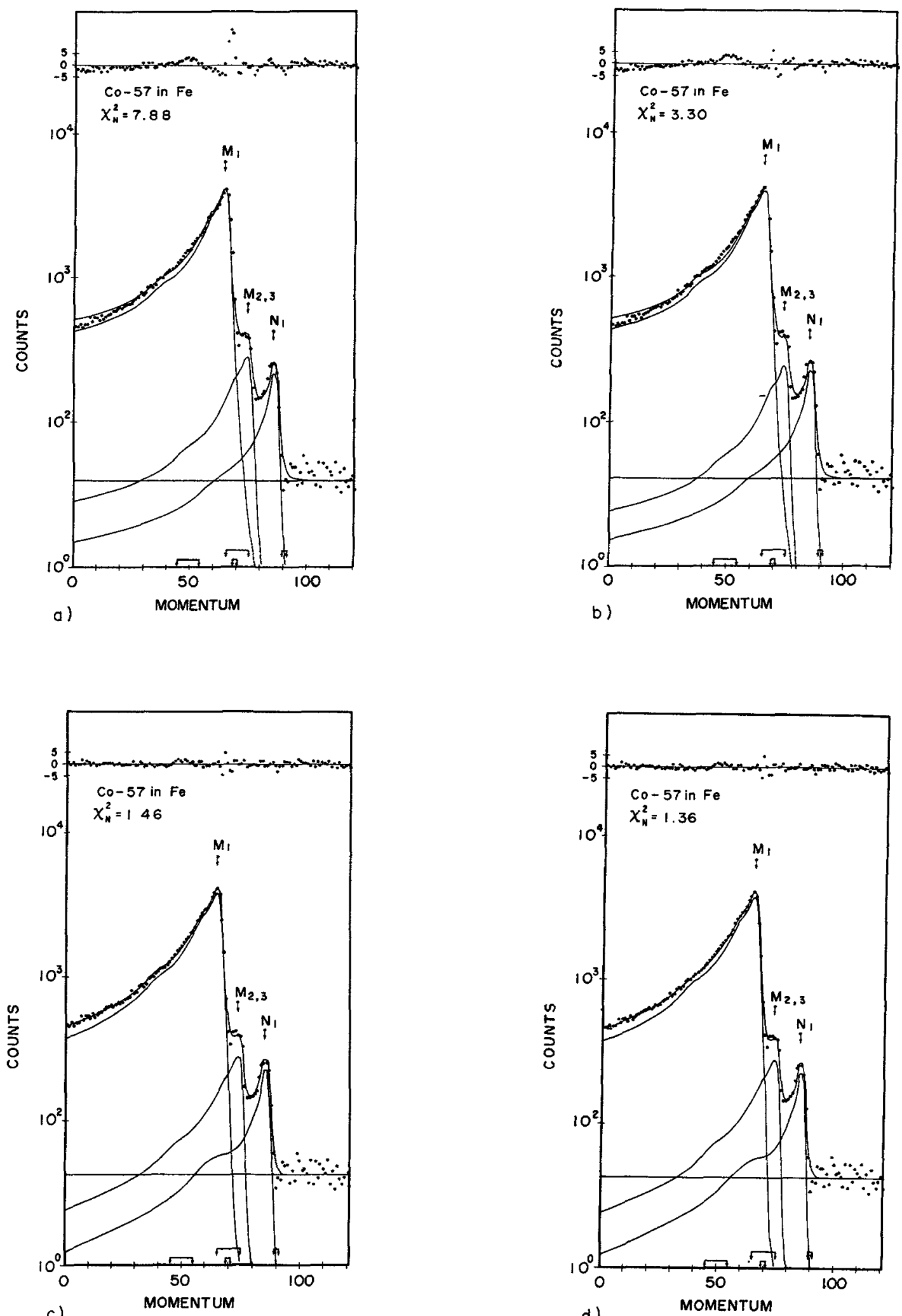

Fig. 1 : Analysis of outer-shell conversion spectrum of $14.4 \mathrm{keV}$ transition of $57 \mathrm{Fe}$ diluted in Fe metal $/ 6$, 8\%. The abscissa $x$ is related to the spectrometer current $I_{s p}$ by $I_{s p}=8 \times 10^{-5} \cdot(x+32405)$ A which is proportional to electron momentum. The arrows on the abscissa designate the continuation regions for $M_{1}$ and $\mathrm{N}_{1}$ lines. The over-all degree of fitting is represented by $x$, while the detail of fitting by $e(x)$

$[N(x) \exp -N(x)$ fit $] / \sigma(x)$ with $\sigma(x)=\left[N(x)\right.$ exp ${ }^{1 / 2}$. a) Adjustment of line and background intensities alone. b) Adjustment of peak positions added. c) Result of five iterations of adjustment of all the parameters including those of profiles. d) Re-adjustment of line and background intensities alone. 


\section{References}

/1/ Shinohara, T. et al., Hyperfine Interactions 1 (1976) 345 .

/2/ Merkert, D., Schule, R. and Martin, B., Max Planck Inst. Rept., MPI H-1973-V33.

/3/ Carlson, T.A., Erman, P. and Fransson, K., Nuc1. Phys. A111 (1968) 371 .

14/ Ewan G.T. and Graham, R.L., "Alpha-, Beta- and Gamma-Ray Sepctroscopy", ed. Siegbahn, K., (NorthHolland Pub1. Comp. Amsterdam) 1966, p. 951.

/5/ Fujuika, M. and Hisatake, K., Phys. Lett. $40 \mathrm{~B}$ (1972) 99 .

/6/ Shinohara, T. and Fujioka, M., Phys. Rev, B7 (1973) 37.

/7/ Porter, F. and Freedman, M.S., Phys. Rev. C3 (1971) 228.

/8/ Fujioka, M. and Shinohara, T., Nuc1. Instrum. Methods 120 (1974) 547 . 